\title{
Surgical repair of a thigh muscle herniation with synthetic mesh
}

\section{Reparación quirúrgica de hernia muscular en muslo con malla sintética}

https://doi.org/10.23938/ASSN.877

\section{S. García-Mata}

\begin{abstract}
We present the case of a 14-year-old female patient with a big muscle hernia in the thigh after extraction of a fascia lata strip to repair bilateral congenital ptosis. After three weeks, a progressive emergence of a large bulge between the two thigh incisions in a standing position was noticeable, with local discomfort, dull pain on exertion and unsightly appearance that worried the patient. On surgery three months later, a large tear in the fascia lata and muscle herniation was revealed. The fascial tear was debrided and a synthetic mesh was applied. Ten years later, the patient confirmed her continued asymptomatic condition.

Muscular hernia of significant size as a consequence of a fascia lata strip harvest is extremely infrequent in adolescents. Surgical repair of big muscular hernias in extremities with synthetic mesh, usually used in groin hernia repair, is an infrequent orthopaedic tool but is safe, easy to apply and inexpensive.
\end{abstract}

Keywords: Muscular hernia. Thigh. Synthetic mesh.

\section{RESUMEN}

Presentamos el caso de una chica de 14 años con una gran hernia muscular en muslo tras extracción de una tira de fascia lata para ser utilizada en cirugía oftalmológica. Tres semanas más tarde era muy evidente en bipedestación un abultamiento entre ambas incisiones, con molestias locales, dolorimiento y preocupación por el aspecto estético. Tres meses más tarde se realizó intervención quirúrgica evidenciándose herniación de parte del músculo vasto externo con gran defecto fascial, que fue desbridado, aplicándose malla no reabsobible de polipropileno. Diez años más tarde la paciente confirmó que permanece asintomática.

La aparición de una hernia muscular de gran tamaño en extremidades de adolescentes como consecuencia de extracción de fascia lata es extremadamente infrecuente. La reparación de hernias musculares de gran tamaño en extremidades mediante malla sintética, utilizada habitualmente en reparación de hernias inguinales, es una técnica rápida, segura y barata a tener en cuenta en cirugía ortopédica.

Palabras clave: Hernia muscular. Muslo. Malla sintética.
Pediatric Trauma and Orthopedic Section. Orthopaedic Surgery Service. Complejo Hospitalario de Navarra. Pamplona. Spain.

Received: December 6, 2019

Revised: June 6, 2020

Accepted: June 22, 2020

\section{Corresponding author:}

Serafín García-Mata

Pediatric Orthopaedic Section

Trauma and Orthopaedic Department

Complejo Hospitalario de Navarra

$\mathrm{C} /$ Irunlarrea, 3

31008 Pamplona

Spain

E-mail: sgarcima@cfnavarra.es 


\section{INTRODUCTION}

A muscle hernia is the protrusion of muscle through a tear in the muscle fascia. It is a soft tissue mass that becomes more prominent with muscle contraction. There are few reported cases of visible palpable bulge due to muscle hernias in the extremities of adults ${ }^{1,2}$, but cases in adolescents are rare. It is clinically diagnosed and can be confirmed by supplemental imaging. Most are asymptomatic; the majority affect the tibialis anterior muscle.

One seldom reported complication of harvesting a longitudinal fragment of fascia lata is muscle hernia, reported in plastic and reconstructive surgery journals. Muscular hernia in the thigh has also been reported rarely: after iatrogenic lesions in total hip arthroplasty $^{3,4}$, as a consequence of direct trauma ${ }^{4}$, on anterolateral thigh perforator flap donor site $^{5-7}$ and after sport-related impact and compartment syndrome decompression ${ }^{6}$. The latter case is similar in localization and extension to the one reported here.

To date, the treatment options for symptomatic extremity muscle herniation in the lower limb documented in the literature include conservative management, wide fasciotomy, direct suture of the defect if possible, tibial periosteal flap or patch repair with fascia lata. Synthetic mesh is a surgical solution rarely reported in the literature.

Orthopaedic surgeons usually do not deal with this rare complication and its repair by techniques related mostly to Plastic surgeons or general surgeons in the groin hernia.

The purpose of this case report is to present a rare complication of fascia lata harvesting in the thigh of an adolescent and the successful surgical repair with a synthetic mesh that is an infrequent orthopaedic tool.

\section{CASE REPORT}

A 14-year-old female patient with bilateral congenital ptosis was recommended to undergo surgery by the Ophthalmology Department, which contacted us to harvest a fascia lata graft for ptosis surgery. Before the eye surgery, a fas- cia lata strip measuring $13 \mathrm{~cm} \mathrm{x} 2.5 \mathrm{~cm}$ was extracted through a 4-cm proximal and distal incision above the iliotibial band. The fascia lata was closed with 3-0 vicryl sutures, the subcutaneous layer with 4-0 vicryl sutures and the skin with 4-0 nylon monofilament intradermal sutures. Since the incisions were very short, closure of the central area was problematic and may not have been completed. A pressure dressing was applied for one week. The subcutaneous intradermal suture was removed after 20 days, at which point a small bulge was discovered between the two incisions. One month later the patient reported progressive emergence of a large bulge that was noticeable in a standing position with local discomfort and dull pain on exertion but was mostly concerned by the unsightly appearance of the bulge, which prevented her from wearing dresses or swimwear (Fig. 1).

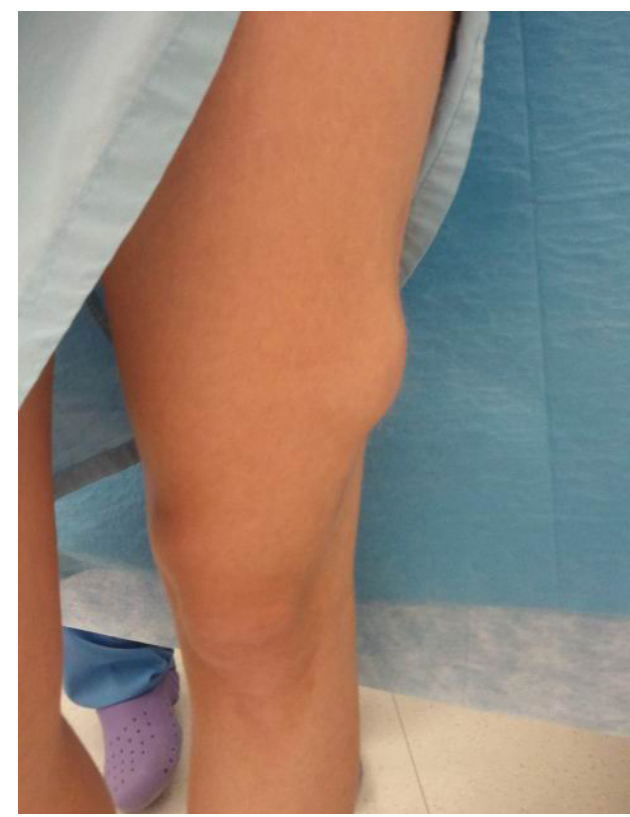

Figure 1. Evident muscle hernia in the lateral side of the thigh.

On surgery, three months later, an examination revealed a large tear in the fascia lata $(15 \times 9$ $\mathrm{cm}$ ) and the herniation of part of the vastus lateralis muscle (Fig. 2A). The fascial tear was debrided and a synthetic mesh (polypropylene non-absorbable synthetic mesh) was applied, before being closed without tension with 3-0 vicryl sutures, reducing and securing the hernia completely (Fig. 2B). 

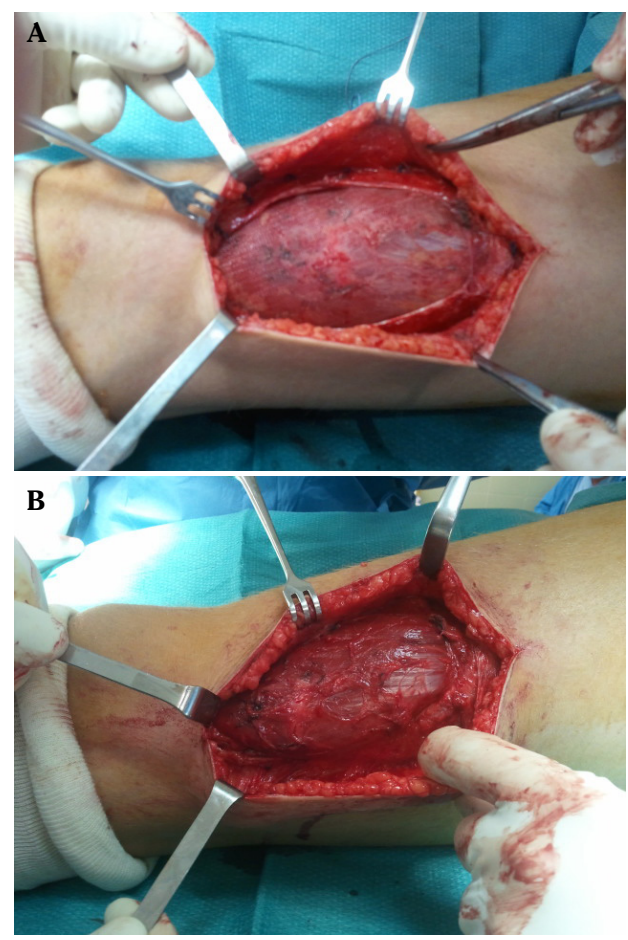

Figure 2. A. Surgical view of the fascia lata defect with a maximum gap of $15 \mathrm{~cm}$. B. The hernia covered by the synthetic mesh.

After surgery, the leg was completely rested for two weeks with compression dressing, followed by a further four weeks on crutches. There were no post-operative complications or relapse. She had complete resolution of the preoperative symptoms and no visible bulging. Four months after surgery, no relapse was observed on the surface of the extremity (Fig. 3). A telephone call with the patient ten years later confirmed her continued asymptomatic condition without recurrence. A visible scar was left on the lateral surface of the thigh.

\section{DISCUSSION}

Muscle hernias are rare in the upper and lower extremities ${ }^{8-10}$, mostly afflicting adult people and are extremely rare in adolescents. They are often primary, small-size and frequently associated with underlying chronic exertional compartment syndrome (CECS $)^{1,11}$. Although most muscle hernias

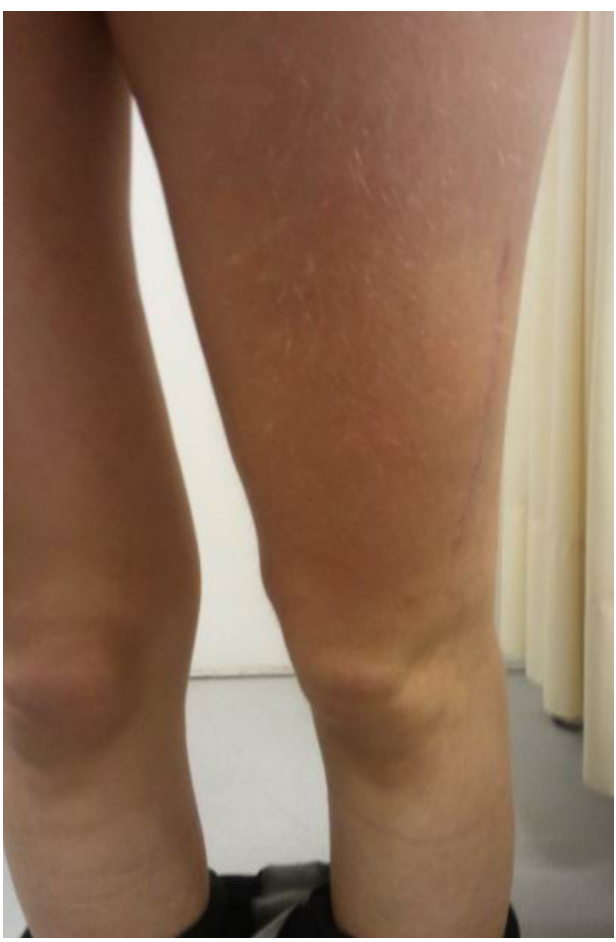

Figure 3. No visible bulging three months after surgery.

are asymptomatic, they can occasionally cause pain or local discomfort, especially in athletes ${ }^{1}$, in addition to the unsightly appearance.

Post-surgical hernias affecting the lower extremities are likely to be larger and require surgical repair due to the onset of symptoms and/or visible unsightly appearance. As expected, the few cases reported in the literature in this regard refer to large fascial wounds, consistent with our patient. Rare cases have been reported of the triggering of symptoms with hernia in the gastrocnemius muscle ${ }^{12}$ or the abductor halluces muscle ${ }^{13}$. Curiously, muscle hernias of a significant size are rarely reported despite the unsightly appearance in visible areas in particular, as was the case with our patient's thigh.

Muscular hernia in the thigh has also been reported very rarely: Dubiel and Wigren in $1974^{14}$ reported muscle herni- 
ation in $36 \%$ of patients after a $10 \times 20 \mathrm{~cm}$ area of fascia lata was harvested for heart valve surgery. Nowadays it has only been reported as case reports ${ }^{3-7}$.

It seems logical that as the size of the fascia lata that is extracted increases, so does the likelihood for wound dehiscence to occur and the subsequent herniation of the vastus lateralis muscle $e^{6,7,15}$. We have only found one study mentioning complications arising from fascia lata harvesting for ptosis surgery ${ }^{15}$ as in the case here reported. In the case presented here, a large amount of fascia was extracted and closure was problematic since there was a proximal and a distal incision, which prevented optimal suturing. Whether the fascia lata graft is extracted through one or two incisions, we believe that complete fascia closure is vital to prevent the risk of post-operative hernia due to tearing of the suture, which is probably what happened in our clinical case.

Supplemental imaging are usually unnecessary because big muscular hernia is a visible and palpable bulge but, in case of doubt, sonography or magnetic resonance imaging (MRI) can be used to confirm this diagnosis or to rule out other diagnoses such as vascular malformations, soft tissue tumors and underlying muscle injury $y^{2,11,13}$. Muscle hernias increase in volume with muscle contraction while vascular malformations increase in volume with vascular engorgement at rest and their volume may decrease with muscle contraction that squeezes the vessels.

Very few publications discuss surgical treatment of muscle hernias not related with CECS, and most are case reports in dermatology, plastic surgery, neurosurgery, military medicine, radiology or general surgery $^{1}$. Management of muscle hernia depends on the size and symptoms. The small muscle hernias are usually treated conservatively as most are asymptomatic, especially secondary hernias in CECS ${ }^{11}$. They are an indicator of the high intracompartmental pressure at exertion and no treatment is indicated. Richards et $\mathrm{al}^{4}$ suggest that limb hernias should not be repaired because the possibility of precipitate an acute com- partment syndrome, but this related to the high-risk areas such as forearm or leg but not the thigh. Surgical options include fasciotomy for small and moderate symptomatic hernias and less-visible areas, or closure of the wound by fascia lata plasty. Fasciectomy can be a useful procedure in case of a symptomatic muscle hernia located in the anterior compartment of the leg or the forearm. In the thigh is not indicated mainly to the aesthetic repercussion (bulging).

Few authors have reported hernia closure using non-synthetic biological grafts. Some authors have reported the use of noncross-linked acellular cadaveric or porcine dermal matrix ${ }^{10}$. We ruled this out in children and adolescents due to the theoretical risks of allografts and xenografts in patients with many years of life theoretically ahead of them, as well as due to the cost. We did not make any fenestration in the "adyacent healthy" fascia lata to promote fibrosis and adhesions. The use of synthetic mesh to repair muscle herniation in the fascia lata has been proven to be useful and safe, as well as easy to apply and cheap. In spite of this, it has not widely reported in the literature: use of polypropylene non-absorbable synthetic mesh in abductor hallucis muscle ${ }^{13}$, anterior tibialis muscle ${ }^{7}$ or the thigh $^{4}$, and use of prolene mesh ${ }^{16}$, polyester mesh (Mersilene) ${ }^{17}$ or vicryl-prolene mesh in gastrocnemius ${ }^{12}$. The patch should not be sutured with tension to the remaining fascial edge as it usually retracts a little and it could trigger chronic exertional compartment syndrome, particularly in susceptible areas (forearm and leg). No relapse has been reported. No donor site morbidity and shorter operative time due to the obviated need for graft harvest are significative advantages for the synthetic mesh.

In conclusion, the extraction of a fascia lata graft for surgical procedures is a safe procedure but it is important to be aware of the possibility of visible residual scarring and the occurrence of a secondary muscle hernia for fascial tear. Large fascial tears should be repaired using synthetic mesh, which offers a simple and reliable solution. 


\section{REFERENCES}

1. Kramer DE, Pace JL, Jarret DY, Zurakowski D, Kocher MS, Micheli LJ. Diagnosis and management of symptomatic muscle herniation of the extremities. A retrospective review. Am J Sports Med 2013; 41: 2174-2180. https://doi. org/10.1177/0363546513493598

2. Nguyen JT, Nguyen JL, Wheatley MJ, Nguyen TA. Muscle hernias of the leg: a case report and comprehensive review of the literature. Can J Plast Surg 2013; 21: 243-247. https://doi. org/10.4172/plastic-surgery.1000834

3. Higgs Je, Chong A, Haertsch P, Sekel R, LeicesTER A. An unusual cause of thigh pain after total hip arthroplasty. J Arthroplasty 1995; 10: 203-204. https://doi.org/10.1016/s08835403(05)80128-7

4. Richards H, Thomas R, Upadhayay S. Polypropylene mesh repair of iatrogenic thigh hernias. Injury 1998; 29: 478. https://doi.org/10.1016/ s0020-1383(98)00086-2

5. Kimata Y, Uchiyama K, Ebihara S, Sakuraba M, Iida $\mathrm{H}$, NaKatsuka $\mathrm{T}$ et al. Anterolateral thigh flap donor-site complications and morbidity. Plast Reconstr Surg 2000; 106: 584-589. https://doi. org/10.1097/00006534-200009010-00009

6. Lipa JE, NovaK CB, Binhammer PA. Patientreported donor-site morbidity following anterolateral thigh free flaps. J Reconstr Microsurg 2005; 21: 365-370. https://doi. org/10.1055/s-2005-915203

7. Odili J, Wilson E, Chana JS. Muscle herniation: A complication at the anterolateral thigh perforator flap donor site. J Plast Reconstr Aesth Surg 2009; 62: 1530-1533. https://doi. org/10.1016/j.bjps.2007.12.071

8. Meredith P, Calonge WM. Polypropylene mesh repair of traumatic hernia of the vastus lateralis: case report and review. Plast Reconstr Surg Glob Open 2019; 7: e2101. https://doi. org/10.1097/gox.0000000000002101

9. Hartmann CEA, Brandford OA, Floyd D. Delayed repair in a case of forearm fascial mus- cle herniation using non-cross-linked acellular porcine dermal matrix. Tech Hand Surg 2012; 16: 166-168. https://doi.org/10.1097/ bth.0b013e31825d5ddf

10. Kozlow JH, Beil RJ, Chung KC. Repair of symptomatic forearm hernias using acellular dermal matrix. Two cases reports. J Hand Surg Am 2010; 35: 2053-2056. https://doi. org/10.1016/j.jhsa.2010.07.035

11. García Mata S, Hidalgo A, Martínez Grande M. Chronic exertional compartment syndrome of the legs in adolescents. J Pediatr Orthop 2001; 21: 328-334. https://doi. org/10.1097/01241398-200105000-00013

12. Bergmann G, Ciritsis BD, Wanner GA, Simmen HP, Werner CML, Osterhoff G. Gastrocnemius muscle herniation as a rare differential diagnosis of ankle sprain: case report and review of the literature. Patient Saf Surg 2012; 6: 5. https://doi.org/10.1186/1754-9493-6-5

13. Nicklas BJ, McEneaney PA, Lichniak JE, Baron RL, BRownell BA. Surgical repair of abductor hallucis muscle herniation: a case report. J Foot Ankle Surg 2010; 49: 488.e5-488.e9. https://doi.org/10.1053/j.jfas.2010.06.020

14. Dubiel WT, Wigren A. Functional status of the lower extremity after resection of fascia lata. Acta Orthop Scand 1974; 45: 599-613. https:// doi.org/10.3109/17453677408989183

15. Wheatcfoft SM, Vardy SJ, Tyers AG. Complications of fascia lata harvesting for ptosis surgery. Br J Oftalmol 1997; 81: 581-583. https:// doi.org/10.1136/bjo.81.7.581

16. Gilardino MS, Loftus JB, Brutus JP. Successful repair of symptomatic extremity muscle herniation with synthetic mesh. Plast Reconstr Surg 2009, 123: 44e-45e. https://doi. org/10.1097/prs.0b013e31819056e9

17. Siliprandi L, Martini G, Chiarelli A, MazzoleNI F. Surgical repair of an anterior tibialis muscle hernia with Mersilene mesh. Plast Reconstr Surg 1993; 91: 154-157. https://doi. org/10.1097/00006534-199301000-00026 
